\title{
Exercise-induced bronchoconstriction: The effects of montelukast, a leukotriene receptor antagonist
}

This article was published in the following Dove Press journal:

Therapeutics and Clinical Risk Management

18 November 2009

Number of times this article has been viewed

\section{James P Kemp}

Clinical Professor of Pediatrics, Division of Immunology and Allergy, University of California School of Medicine, San Diego, CA, USA
Correspondence: James P Kemp 9610 Granite Ridge Drive, Suite B, San Diego, CA 92123, USA

Tel +| 858292 | | 44 x. 175

Fax + I 760765 |23।

Email jpk3355@gmail.com
Abstract: Exercise-induced bronchoconstriction (EIB) is very common in both patients with asthma and those who are otherwise thought to be normal. The intensity of exercise as well as the type of exercise is important in producing symptoms. This may make some types of exercise such as swimming more suitable and extended running more difficult for patients with this condition. A better understanding of EIB will allow the physician to direct the patient towards a type of exercise and medications that can result in a more active lifestyle without the same concern for resulting symptoms. This is especially important for schoolchildren who are usually enrolled in physical education classes and elite athletes who may desire to participate in competitive sports. Fortunately several medications (short- and long-acting $\beta_{2}$-agonists, cromolyn, nedocromil, inhaled corticosteroids, and more recently leukotriene modifiers) have been shown to be effective in preventing or attenuating the effects of exercise in many patients. In addition, inhaled $\beta_{2}$-agonists have been shown to quickly reverse the airway obstruction that develops in patients and continue to be the reliever medications of choice. Inhaled corticosteroids are increasingly being recommended as regular therapy now that the role of inflammation and airway injury has been identified in EIB. With the discovery that there is a release of mediators such as histamine and leukotrienes from cells in the airway following exercise with resulting airway obstruction in susceptible individuals, interest has turned to attenuating their effects with mediator antagonists especially those that block the effects of leukotrienes. Studies with an oral leukotriene antagonist, montelukast, have shown beneficial effects in adults and children aged as young as 6 years with EIB. These effects can be demonstrated as soon as two hours and as long as 24 hours after administration without a demonstrated loss of a protective effect after months of treatment. The studies leading up to and resulting in an approval of montelukast for EIB for patients aged 15 years and older are reviewed in this paper.

Keywords: asthma, exercise, bronchoconstriction, bronchospasm, leukotrienes, montelukast

Probably the first description of exercise-induced bronchoconstriction (EIB) was during the 2nd century when the Greek physician Aretaeus the Cappadocian wrote: "If from running, and exercise, and labor of any kind a difficulty of breathing follows it is termed asthma". ${ }^{1}$ Fast-forward to the current era where this condition not only affects millions worldwide but has been an issue for the International Olympic Committee., ${ }^{2,3}$ Their concern largely results from the use of performance-enhancing drugs during athletic competition. This response is not surprising since many bronchodilators such as salbutamol (albuterol) and methyl xanthenes (theophylline, aminophylline) can have effects on the cardiovascular system in higher than usually prescribed doses. 
However, in a recent review of 19 placebo-controlled studies, it was found that in 17 of the studies the effects of inhaled $\beta_{2}$-agonists in doses commonly used to prevent EIB did not result in ergogenic effects in competitive athletes. ${ }^{4}$ Although the World Anti-Doping Agency has included $\beta_{2}$-agonists in their list of prohibited drugs, both short- and long-acting $\beta_{2}$-agonists are exempt when inhaled. ${ }^{5}$ This information, along with pre-competition testing, ${ }^{6}$ has allowed athletes with EIB to compete in Olympic Sports without the threat of disqualification as has occurred in the past. Concerns that athletes taking inhaled corticosteroids (ICS) for asthma control may be using medications that increase muscle mass as can be obtained from anabolic steroids have also been dismissed as appropriate doses of ICS have shown the ability to reduce the severity of EIB without this or other adverse effects. $^{7}$

Although EIB and exercise-induced asthma (EIA) are often used interchangeably, it is becoming common to use EIB for patients who have a diagnosis of asthma and wheeze after exercise and use EIA in individuals who only have airway obstruction following exercise, but are otherwise free of asthma. EIB has also been called exercise-induced airway narrowing ${ }^{8}$ by $\mathrm{McFadden}$ who states that these terms "describe a condition in which vigorous physical activity triggers acute airway narrowing in people with heightened bronchial reactivity". He further points out that "exercise in EIA merely serves as the means by which ventilation rises. Hyperpnea is the key element, and it is immaterial how it comes about." 8

EIB is considered a form of airway hyperresponsiveness (AHR) and its expression increases and decreases in relationship to the degree of underlying airway reactivity ${ }^{9}$ and the severity of the underlying asthma. ${ }^{10}$ The importance of AHR in EIB and asthma was emphasized by a recent study which showed that children with increased airway responsiveness in late infancy and childhood had a greater risk of developing asthma than their counterparts who did not have increased airway responsiveness in infancy. ${ }^{11}$

EIB has been reported present in as few as $40 \%$ and as many as $90 \%$ of patients with asthma. ${ }^{12}$ Some of this difference can be accounted for by the severity of the patient's asthma, the intensity, the duration, as well as the type of exercise challenge employed.

In patients with asthma, exercise-induced symptoms can be used as a marker of incomplete asthma control indicating a need for additional controller medications.

Individuals with allergic rhinitis without asthma have been reported to have a prevalence of EIB of up to $40 \%{ }^{12}$ and can be found in up to $13 \%$ of otherwise normal individuals when the challenge test is adequate. Therefore this is a common condition which may go unrecognized for years especially in individuals who do not or choose not to exercise.

Interestingly the prevalence of EIB and AHR are increased in elite athletes. ${ }^{13}$ It is suspected that the repeated high ventilation required during training may irritate the airways and result in mediator release and airway injury. This would be particularly likely during periods of air pollution, exposure to pollens, or extreme cold air. This effect may be somewhat reversible after cessation of endurance training. ${ }^{14}$

EIB usually occurs following 5-8 minutes of vigorous exercise, enough to result in prolonged hyperventilation. Frequently the degree of EIB is recorded as the maximum percent fall in forced expiratory volume in one second $\left(\mathrm{FEV}_{1}\right)$ from baseline following the exercise period. ${ }^{15}$ At other times the degree of airway obstruction may be recorded as the entire time from when lung function as demonstrated by a change in $\mathrm{FEV}_{1}$ falls below baseline until this value returns to $5 \%$ of pre-exercise $\mathrm{FEV}_{1}$ or the patient requires relief from an inhaled short-acting $\beta_{2}$-agonist (SABA). This measurement takes into account the entire time that the subject has airway obstruction and not just the maximum effect of the test $^{16}$ (Figure 1).

To document EIB, patients can be exercised in a laboratory on a treadmill or exercycle for 5-8 minutes at a heart rate estimated to approach $80 \%-90 \%$ of maximum (approximates $80 \%$ oxygen consumption), which is determined by the patients' age. This level of exercise is usually enough to

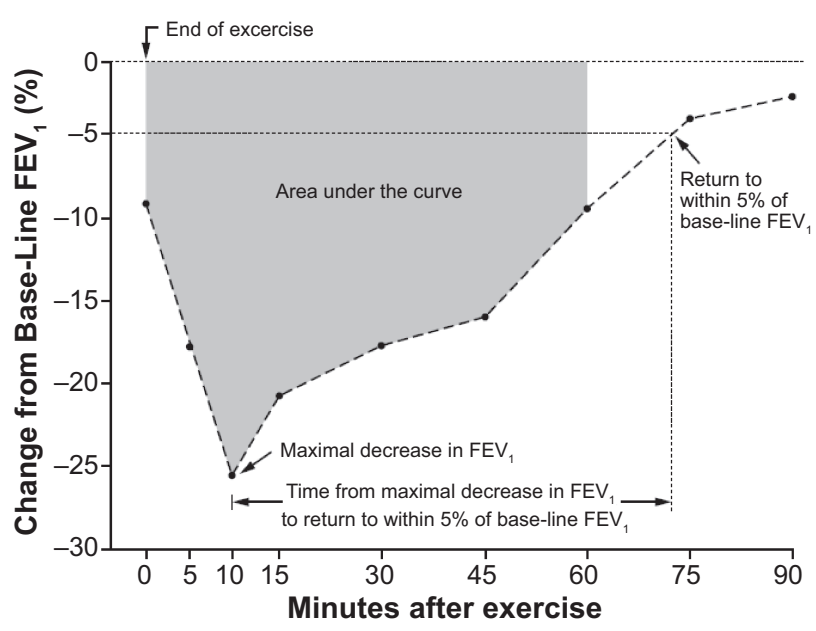

Figure I End points used to assess the degree of exercise-induced bronchoconstriction.The following end points were assessed: the area under the curve for the percent decrease in $\mathrm{FEV}$, in the first 60 minutes after exercise, the maximal decrease in $\mathrm{FEV}$, after exercise, and the time from the maximal decrease in $\mathrm{FEV}$, to the return to within $5 \%$ of the $\mathrm{FEV}$, value before exercise.

Abbreviation: $\mathrm{FEV}_{1}$, forced expiratory volume in one second. 
induce EIB in susceptible subjects. ${ }^{15}$ The effect on the airways maybe further intensified by having the subject breathe cool dry air through their mouth while exercising. ${ }^{17}$ This can be accomplished by inflating a breathing bag with compressed air from which the subjects breathes. A two-way valve allows for air to be exhaled into the laboratory. To insure the subject is breathing through the mouth a nose clip must be used. Some subjects are able with nasal breathing, to warm and humidify the air enough that it may be difficult to demonstrate a significant fall in $\mathrm{FEV}_{1}$ as a response to the challenge test. ${ }^{17}$ In a majority of subjects with mild asthma or in those only having EIB, the fall in $\mathrm{FEV}_{1}$ is usually less profound, self limited, and resolves within an hour without medication. Other subjects may need to be rescued with an inhaled $\beta_{2}$-adrenergic bronchodilator such as salbutamol (albuterol) if they become extremely symptomatic or have a profound fall in $\mathrm{FEV}_{1}$ which does not reverse quickly.

Since the cause of the airway narrowing is not a result of the exercise per se, but as a result of prolonged hyperventilation, it is possible to induce a similar response in the airway with isocapnic voluntary hyperventilation. ${ }^{18,19}$ Also hypertonic aerosols ${ }^{19,20}$ can be used to induce an airway response in patients with EIB. However these tests are an indirect test of EIB and should be considered more of a measurement of AHR even though there may be excellent correlation in many patients who have EIB.

It is possible to demonstrate that a patient has EIB during typical exercise in a real-world setting. One common method is to have the individual exercise on a playground or athletic field for about five minutes using a peak flow meter to obtain flow values before and after the exercise period. A fall of peak expiratory flow (PEF) of $15 \%$ or greater would indicate a change in air flow enough to suggest a diagnosis of EIB. However, it is important to remember that this realworld challenge may not duplicate all exercise situations the subject is exposed to, nor be sufficiently vigorous to cause a $15 \%$ fall in PEF or $\mathrm{FEV}_{1}$. It has been shown that the degree of EIB in children depends on the exercise load. A study of children who exercised at $85 \%$ of maximum showed a fall in $\mathrm{FEV}_{1}$ of $8.8 \%$, whereas when they exercised at $95 \%$ of maximum, the fall in $\mathrm{FEV}_{1}$ was $25.1 \%{ }^{21} \mathrm{~A}$ false negative test, if suspicions of EIB are high, should be repeated in the laboratory under more controlled conditions as described before. If this is not feasible then a trial of an inhaled $\beta_{2}$-agonist before exercise might result in a clinical response of blocking airway narrowing, which allows the patient to be active until more definitive testing can be done. In such situations, close follow up is very important because other respiratory conditions such as vocal cord dysfunction ${ }^{22}$ or other upper airway obstructions, as well as cardiovascular events, can be manifested during or immediately after exercise. In a study that reported the findings of 11 patients who reported cold air dyspnea with exercise, no bronchoconstriction could be demonstrated after exercise provocation, but capsaicin cough sensitivity was increased and end-tidal $\mathrm{CO}_{2}$ decreased among the patients. ${ }^{23}$ The authors concluded that exercise-induced dyspnea may be associated with hypocapnia from hyperventilation and increased capsaicin cough sensitivity. The diagnosis of exercise-induced asthma should be questioned when the patient has no signs of bronchoconstriction. Many of these possible diagnoses can be ruled out by additional testing. However, spirometric evaluation remains the best test to consider initially. This in part is because only about $50 \%$ of patients can correctly assess their degree of airway obstruction when asked ${ }^{24}$ and it is the change in airway caliber which is measured by a change in $\mathrm{FEV}_{1}$ that is the hallmark of EIB.

Since EIB is considered a form of AHR by many investigators, most patients with this condition also respond with airway obstruction when challenged with bronchoprovocation agents such as inhaled hypertonic aerosols ${ }^{19}$ or methacholine. ${ }^{25}$ More recently inhaled mannitol, ${ }^{26,27}$ although not yet approved for bronchoprovocation testing in all countries including the United States has been shown to correlate very well with standard exercise tests in both elite athletes ${ }^{26}$ and in asthma patients ${ }^{27}$ who have EIB.

The observation that cool and/or dry air increases the possibility of EIB led to two theories of its etiology that were debated for years. ${ }^{28,29}$ One theory concerned a cooling and the other a dehydration of the cells that line the airways. Recently EIB is believed to occur because of an injury to the airway epithelium. ${ }^{30}$ Increased concentrations of airway columnar epithelial cells, eosinophils, and leukotrienes were seen in induced sputum of subjects with EIB compared to those who did not have significant bronchoconstriction following exercise ${ }^{31}$ In another study, the same group found decreased concentrations of prostaglandin $\mathrm{E}_{2}$ and thromboxaine $\mathrm{D}_{2}$ in the sputum of patients with EIB. ${ }^{32}$ In elite athletes it has been proposed that airway injury with resulting plasma exudation and cell movement into the airways occurs contributing to the pathogenesis of EIB. ${ }^{30,32}$ Stimuli such as prolonged hyperventilation on an injured epithelium are believed to produce a dehydration and a resulting degranulation of airway cells with a release of inflammatory mediators such as histamine and leukotrienes. It is the effect of these mediators in the airway that lead to constriction of smooth muscles, stimulation of mucous-producing glands, and microvascular leakage 
with resulting airway edema. The end result is one of airway narrowing and the typical symptoms of asthma: wheezing, coughing, chest tightness, shortness of breath, and dyspnea following exercise.

Characteristically, symptoms begin within a few minutes after the exercise period is completed. The degree of change in airway function is reflected by a measurable decrease in $\mathrm{FEV}_{1}$ or PEF of at least 10\% although many believe there should be a change of $15 \%$ or greater. Following the maximum drop in $\mathrm{FEV}_{1}$, the values usually return to baseline spontaneously within one hour. However, when extreme airway obstruction occurs, improvement may need to be obtained with the inhalation of a $\beta_{2}$-agonist such as salbutamol (albuterol). Actually both short- or long-acting $\beta$-agonists (LABAs) can result in an improvement in symptoms and a more rapid return of the $\mathrm{FEV}_{1}$ to normal. ${ }^{8}$

EIB occurs often after prolonged exercise such as distance running which would duplicate a 5-8 minute exercise test in the laboratory. Shorter periods of running such as a $100 \mathrm{~m}$ race, which does not result in prolonged hyperventilation is often insufficient to induce symptoms. Although both allergy and asthma occur in elite summer athletes, ${ }^{33}$ it has been thought that athletes who swim for exercise are not as likely to develop EIB as those that run. This was presumed to be because when swimming, the ambient air near the surface of the water is highly humidified and may be warmer. However, it has been shown that while swimming indoors in chlorinated pools, the athlete is exposed to chloramines which have been shown to be asthmagenic ${ }^{34}$ and a prevalence of EIB as high as $29 \%$ has been reported in competitive swimmers. ${ }^{35}$ Nevertheless it is possible for athletes with asthma induced by running to win Olympic medals in swimming competitions (Kurt Grote: Gold Medal winner at the 1996 Atlanta Olympics) and for many patients there are beneficial effects as well as potential adverse effects from swimming. ${ }^{34}$ The prevalence of EIB and AHR are increased in some elite athletes. ${ }^{36,37}$ This may be due to the extreme hyperventilation that occurs during training in some sports. Training all year in climates that require breathing cold dry air or during seasonal allergy periods for those athletes who are atopic may have injurious effects on the airways. ${ }^{38}$ Other observations have been made recently. A study reported a higher prevalence of methacholine-induced AHR in females (F: 60\% vs $\mathrm{M}: 21.5 \%$ ) and reported symptoms during exercise (F: 37.1\% vs M: $16.9 \%$ ), even though there was a similar prevalence of physician-diagnosed asthma in their male counterparts. ${ }^{39}$

In a study of children with mild asthma, exercise training decreased bronchial responsiveness to methacholine ${ }^{40}$ and some patients become less subject to the airway obstructive effects of exercise following exercise conditioning. This may be a result of better conditioning with a more efficient use of oxygen and less hyperventilation during exercise. It may be that decreasing exercise gradually allows for a slower rate of rehydration and warming of the airway. Following exercise in $40 \%-50 \%$ of patients with EIB there may be a refractory period of 1-3 hours during which additional exercise ${ }^{41}$ or hyperventilation ${ }^{42}$ does not induce airway obstruction at least to the same degree. This finding becomes an important consideration when doing repeated exercise challenges as might occur in clinical drug trials looking at duration of the pharmacotherapeutic effect of the medication being studied. Also this refractory period may allow athletes to decrease the effects of exercise prior to competition. ${ }^{43}$

For patients with more severe degrees of asthma, exercise without medication is often impossible. The degree of airway obstruction that pre-exists before exercise is such that they are unable to exercise sufficiently to develop EIB, although there is no relationship between baseline $\mathrm{FEV}_{1}$ and severity of EIB. ${ }^{44}$ Inactivity as a consequence of asthma is not considered to be acceptable in the asthma management guidelines ${ }^{45,46}$ and indicates the need for additional controller medications in most patients so that their life can be normalized as much as possible. Recently a study showed that regular physical activity reduced the risk of asthma exacerbations in older (mean age 63 years) women. ${ }^{47}$ Although this prospective study was not able to evaluate this effect on the subgroup of patients with EIB enrolled in the study the beneficial effects of exercise on asthma was clearly demonstrated.

Fortunately there are several medications that can help the patient with EIB exercise at higher cardiovascular levels for longer periods of time. Most of these medications are well known pharmacotherapeutic agents used to treat persistent asthma. However, most have also been found to be effective in patients who have intermittent asthma with symptoms following exercise. Since asthma is considered by most experts as a heterogenous disorder, not all medications will work equally well in all patients. ${ }^{48,49}$ This review will briefly look at these medications and their effect on EIB but will focus on the leukotriene receptor antagonist (LTRA), montelukast, the latest to receive drug regulatory approval in many countries for the management of EIB in adults.

\section{Medications}

\section{Inhaled anticholinergics}

Although useful drugs in treating chronic obstructive pulmonary disease (COPD), most studies with drugs in this 
category have shown very little effect as monotherapy in most types of asthma. This is true in the majority of studies dating back to the 1980 s in patients with EIB. ${ }^{50-53}$ Although immediately after inhalation there can be demonstrated a modest improvement in $\mathrm{FEV}_{1}$, presumably from a decrease in bronchomotor tone, there is little effect on the prevention of EIB and in the majority of patients they are not used as such.

\section{Inhaled corticosteroids}

Because asthma is characterized by AHR, most patients who exercise to a significant level will have EIB. Because current asthma treatment guidelines recommend regular controller medications for all patients who have more than mild well controlled asthma ${ }^{45,46}$ many of these patients will be taking ICS already. The effect of ICS on airway inflammation in both adults and children when given for at least four weeks will in many cases be enough to decrease or eliminate EIB. ${ }^{54}$ Therefore, before starting additional medications for EIB, it is important to be certain how well a patient's asthma is being controlled with the medications they are supposed to be taking. Since adherence (compliance) with all asthma controller medications including ICS is extremely poor, ${ }^{55}$ it is important to review the patient's actual adherence to their previously prescribed medications. As obvious as it may seem, it is commonly overlooked in practice that the best medication, improperly or inadequately taken, will have a subtherapeutic effect. All that may be needed in such patients is to reestablish their prior treatment plan.

\section{$\beta$-adrenergic agonists}

Most patients respond well to $\beta_{2}$-agonists for both the prevention of EIB when given prior to the exercise period or post-exercise to reverse the obstruction that has occurred. ${ }^{56}$ The effect of these medications especially when taken by inhalation is rapid which results in their being the most commonly prescribed for patients with asthma and EIB. This is true of both SABAs and LABAs ${ }^{57,58}$ such as salmeterol ${ }^{59,60}$ or formoterol. ${ }^{61,62}$ The later are usually used as controller medications, preferably with an ICS. However, as has been reported with SABAs, when LABAs are regularly taken, tolerance to their original effect ${ }^{63,64}$ rapidly develops. This often results in shorter times of protection although the protection is frequently sufficient to exercise 3-4 hours after administration. ${ }^{59}$ As a response to reports of an increase in deaths when patients have taken LABAs, ${ }^{65,66}$ a recent US Food and Drug Administration (FDA) advisory panel voted that the risk of taking single entity salmeterol and formoterol outweighed their benefit and recommended that LABAs only be used in combination with an $\mathrm{ICS} .{ }^{67}$ This may result in the removal of single entity LABAs from the US market for the treatment of asthma. However since this increase in adverse effects from single entity LABAs has not been seen in patients with COPD, these drugs will still remain as a treatment option for EIB in the United States although when used, will be used off label. If elimination or further restriction of single entity LABAs occurs because patients with EIB have AHR, a combination of a LABA with an ICS is very likely to have additive effects and may result in a better outcome than using monotherapy alone. Many asthma experts believe that a LABA should always be used with an ICS, although there is inadequate evidence that doing so decreases risk of serious adverse events. ${ }^{67,68}$

\section{Cromones}

Cromolyn sodium and nedocromil sodium are not used as frequently today, ${ }^{69-71}$ although effective and approved in most countries for EIA. Their popularity waned in part because of the current availability of more effective, faster, longer acting, and easier to take medications. Because of their excellent safety profile, they were used extensively in children with EIB as well as in children with more persistent asthma. They can work alone or in combination when other medications have failed to block the airway response to exercise significantly. It is important to consider their use especially when other medications have been proven inadequate since their mechanism of action is different. They are now generic drugs in all countries and should also be considered when the expense of medication is a concern.

However, since the removal of chloroflurocarbon propellants and the current nonavailability of hydrofloroalkane inhalers for either medication, they will only be available as dry powder inhalers and a nebulizable solution, which further limits their availability. Currently they are available in some countries such as New Zealand and Australia in a dry powder formulation. The nebulized formulation is available in the US.

\section{Leukotriene receptor antagonists and leukotriene synthesis inhibitors}

With the recognition that elevated levels of leukotrienes are found in the airway of patients with $\mathrm{EIB}^{72,73}$ as well as in patients with acute and chronic asthma, ${ }^{74}$ the effects of LTRA $^{75-78}$ and inhibitors of leukotriene synthesis ${ }^{79,80}$ began to be explored. Zafirlukast, the first LTRA to be approved in the US for asthma, showed protection against EIB in both adults ${ }^{81}$ and children ${ }^{82}$ when given eight hours before an exercise test. 
Pranlukast showed a similar protective effect after 14 days of treatment in a Japanese study. ${ }^{83}$ Other inhibitors of the activity of leukotrienes such as ziluton, a leukotriene synthesis inhibitor, have also shown beneficial effects in patients with EIB. ${ }^{80}$ In most countries, only the LTRA montelukast has received approval by drug regulatory agencies for prevention of EIB. What follows is a review of the studies that resulted in its approval in adults and studies that may lead to its approval in children.

\section{Montelukast for EIB}

Montelukast, a LTRA available as oral single daily medication, was first approved in the US in March 1998 for the treatment of persistent asthma in adults (10 $\mathrm{mg})$ and children as young as one year of age ( $5 \mathrm{mg}$ or $4 \mathrm{mg}$ ). Later in some countries it was given an approval for the treatment of allergic rhinitis and more recently approval for the prevention of EIB.

The duration of clinical effect of montelukast in treating persistent asthma was in part determined by using the model of EIB. In two separate exercise studies, it was found that there was an effect lasting for 24 hours after giving a single $10 \mathrm{mg}$ dose of montelukast in adults with EIB, even though the half life of montelukast in the blood is only about five hours. ${ }^{84}$ In a study published in the New England Journal of Medicine, ${ }^{85} 110$ adults demonstrated a positive effect of montelukast on EIB for 12 weeks (Figure 2). In this study, subjects were given either a placebo or montelukast $10 \mathrm{mg}$ prior to exercising on a treadmill at a rate estimated to be $80 \%$ of maximum cardiac output for five minutes while breathing cool dry air. Following this challenge, subjects were observed for one hour to determine at what point their breathing returned to baseline. Patients who developed severe airway obstruction

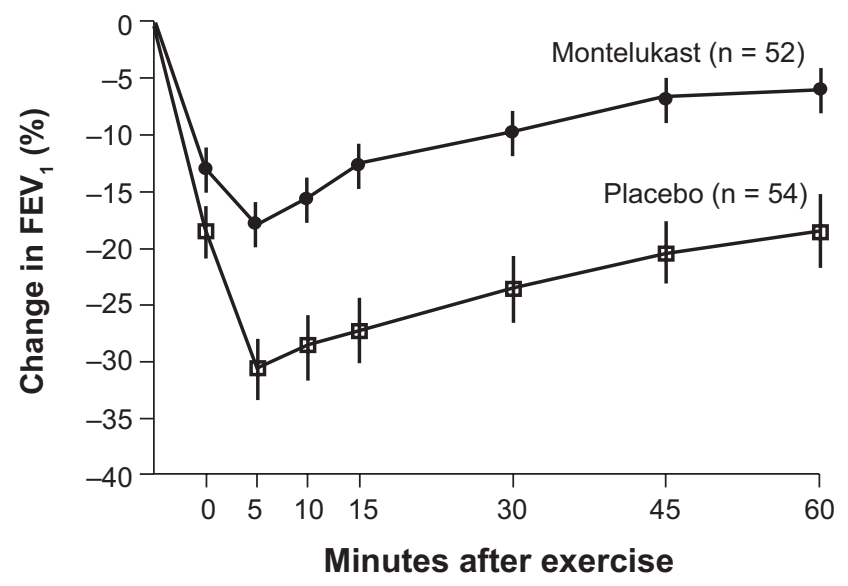

Figure 2 Mean $( \pm$ SE) changes in FEV, after exercise challenge after 12 weeks of treatment with montelukast or placebo. Treatment with montelukast was associated with a significant $(P=0.002)$ reduction in exercise-induced bronchoconstriction. Abbreviation: $\mathrm{FEV}_{1}$, forced expiratory volume in one second. were allowed to use a SABA for relief during the 60 minute post-exercise observation period. Exercise challenges during the study were performed 20-24 hours post dosing at weeks 4,8 , and 12 and at the end of a two-week wash out period. There was a $47.4 \%(p=0.002)$ improvement in the montelukast subjects over the placebo group in the area under the $\mathrm{FEV}_{1}$ curve during the first 60 minutes following exercise. After 12 weeks of treatment the patients on placebo had a mean maximum fall in $\mathrm{FEV}_{1}$ of greater than $30 \%$ after the exercise period whereas the patients pretreated with montelukast had a $18 \%$ decrease. Those patients on montelukast had a more rapid return of airway function toward their baseline than those receiving a placebo and needed rescue $\beta_{2}$-agonists less often. The study indicated that a blockage of leukotriene receptors in the airway can be therapeutically effective in some patients with EIB. Tolerance was not seen with continued montelukast treatment during the 12 weeks of treatment. The effect of this medication on exercise induced asthma was essentially the same at the beginning and end of the study. In addition no rebound effect was seen after montelukast was discontinued (Figure 3).

The initial multiple dose montelukast pediatric EIA study was performed in 6-14 year olds in a double blind, multicenter, placebo controlled, two-period crossover study. ${ }^{86}$ Children received a $5 \mathrm{mg}$ chewable montelukast tablet once daily instead of the $10 \mathrm{mg}$ adult dose. The first exercise challenge was performed after two days of dosing. A standard exercise challenge (as described before) was done 20-24 hours after the last dose of montelukast or placebo. At least a four day interval occurred between the two treatment periods in this crossover study. In these 6-14-year-old subjects, a similar attenuation of the effects of exercise was seen as in the adult study (Figure 4). The maximum decrease in $\mathrm{FEV}_{1}$ in the placebo patients was about $24 \%$ whereas it was $13 \%$ in the montelukast-treated group. As in the adult study, the montelukast patients returned to baseline $\mathrm{FEV}_{1}$ faster with less need for $\beta_{2}$-agonist rescues than the subjects given a placebo. Since it is customary in the US for the FDA to require two separate studies to obtain a new indication for a medication (montelukast for 6-14 year olds with EIB), an additional study is being completed to obtain this indication for children.

With an appropriate antigen inhalation challenge, most allergic asthma patients will have an immediate asthma reaction within a few minutes following the challenge. This is thought to be the result of the release of preformed mediators from airway cells. In addition following the immediate reaction and a return to baseline, some subjects will have a delayed reaction 3-5 hours later, with a corresponding fall in $\mathrm{FEV}_{1}$. 

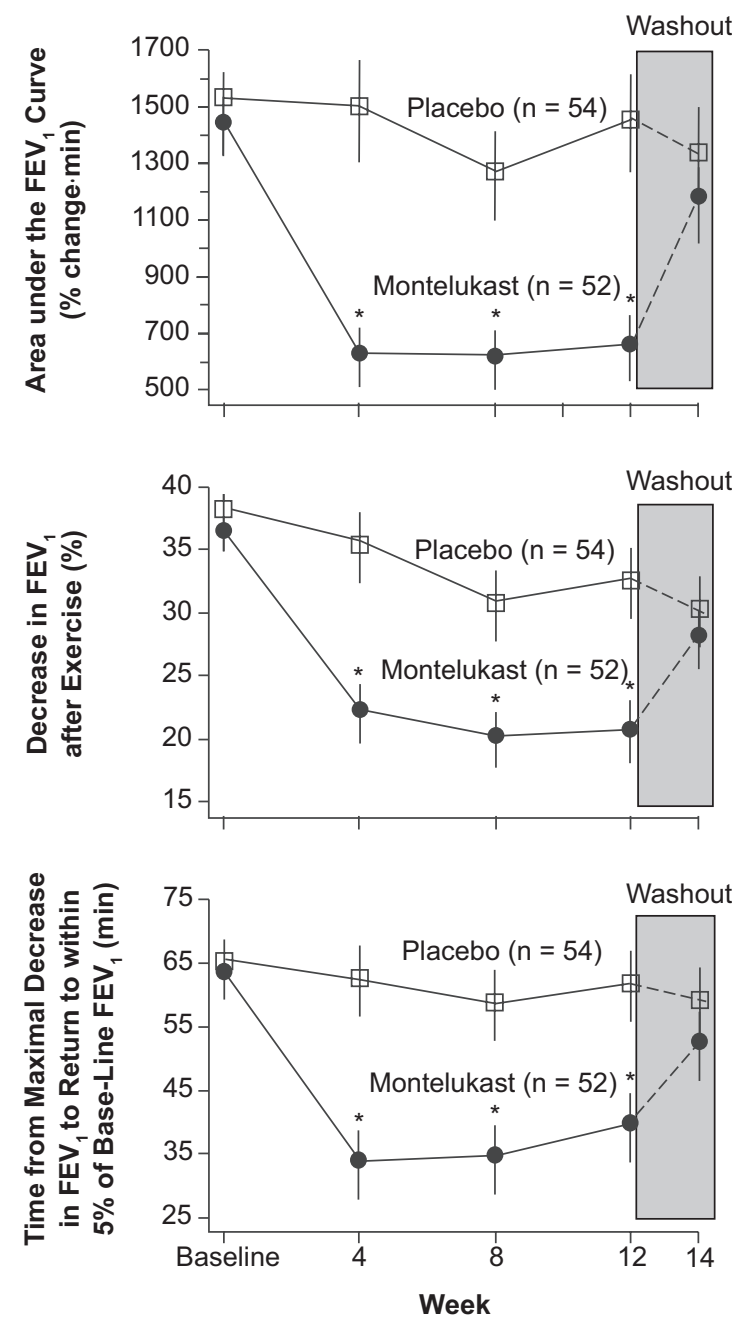

Figure 3 Effects of treatment with montelukast and placebo on the three end points over time. During the two-week washout period, all patients received placebo in a single-blind fashion. Values are means $\pm \mathrm{SE}$. Asterisks indicate significant differences $(P<0.05)$ between groups.

Abbreviations: $\mathrm{FEV}_{1}$, forced expiratory volume in one second; $\mathrm{SE}$, standard error.

This late reaction is believed to be the result of inflammatory cell migration into the airway. ${ }^{87}$ There is no consensus that a delayed response to exercise occurs in EIB, ${ }^{88,89}$ however such a reaction has been reported in some studies. ${ }^{90,91}$ Attenuation of a late response following exercise in the laboratory would give further insights on the mode of activity of a therapeutic agent such as montelukast and the role of leukotrienes in the process of inflammatory airway diseases such as EIB.

In a small double-blind randomized pediatric EIB study, montelukast was shown to block a late reaction that had occurred in five subjects. ${ }^{92}$ These subjects were aged 7-16 years. Although only five of the 22 subjects enrolled in the study demonstrated a late phase response to exercise, once-daily treatment with montelukast $5 \mathrm{mg}$ for one week attenuated the immediate response and abolished

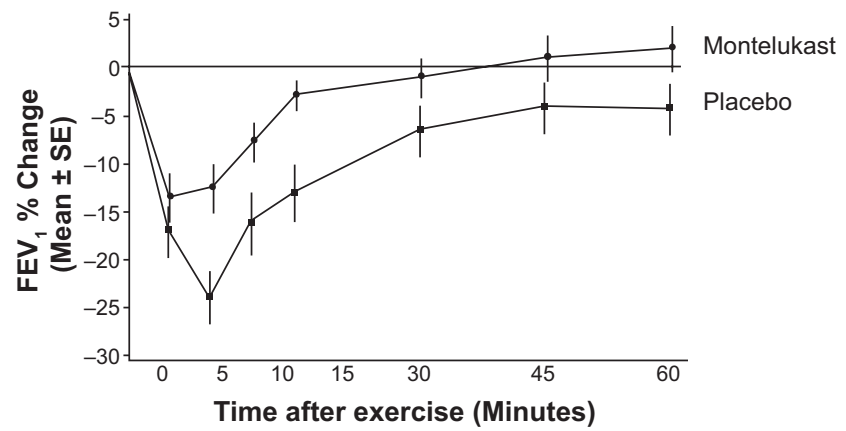

Figure 4 Mean percent change in FEV, at time points from 0 to 60 minutes after exercise. Abbreviations: $\mathrm{FEV}_{\text {, }}$, forced expiratory volume in one second; $\mathrm{SE}$, standard error.

the late phase response in these five subjects. This effect was independent of the use of ICS. Since leukotrienes are released during the immediate and late phase of an allergic reaction, such an attenuation of both responses demonstrates that leukotrienes in the airway have more than just an immediate effect on airway smooth muscle. They also are proinflammatory mediators that are involved in the late reaction.

The majority of clinical studies with montelukast looked at its effect on EIB after at least two days of dosing. The positive effects seen are important for patients with more persistent asthma who take controller therapy daily for symptom control. The effect of a single dose of montelukast in patients who only have EIB and do not take medication daily was evaluated in a study that demonstrated that an initial single dose of montelukast was able to attenuate the effect of exercise two hours after administration. ${ }^{16}$ This was a double-blind crossover study in 62 patients with EIB. Challenge was performed 2, 12, and 24 hours after a $10 \mathrm{mg}$ montelukast dose. The primary end point was the maximum percent fall in $\mathrm{FEV}_{1}$ during 60 minutes after exercise. This end point was improved in the montelukast patients: $10.8 \%$ decrease in $\mathrm{FEV}_{1}$ at two hours, $8.4 \%$ at 12 hours, and $8.3 \%$ at 24 hours post-dose compared to the placebo patients: $22.3 \%$ decrease in $\mathrm{FEV}_{1}$ at two hours, $16.1 \%$ at 12 hours, and $16.9 \%$ at 24 hours. Less patients in the montelukast group required $\beta_{2}$-agonist rescue. A quicker time to recovery after challenge was found in the montelukast patients as was a smaller area under the curve for percent fall in $\mathrm{FEV}_{1}$ during 60 minutes after challenge.

The duration that a medication can attenuate EIB is important to many athletics and patients who may exercise at different times of the day or who do not wish to take medication immediately before exercise. SABAs have been used for years to prevent the effects of exercise in patients with EIB. However, they usually have duration of effect of only $2-4$ hours which may not adequately protect the indi- 
vidual who may wish to exercise late in the day or at school following a morning dose of medication. Studies with LABAs have shown a protective effect on EIB of 10-12 hours, , $^{57,62}$ which makes them a much better therapeutic choice in such situations. However as discussed previously, with the regular use of LABAs tolerance is common, resulting in a decrease in duration of protection. ${ }^{93,94}$ Since LTRAs have shown protection against EIB for 24 hours, how do they compare with LABAs in clinical studies?

In order to study the protective effect of a LTRA with a LABA, a three-way crossover study with montelukast, salmeterol, and placebo was done in 47 patients aged 15-44 years with demonstrable EIB. ${ }^{95} \mathrm{FEV}_{1}$ was measured at 2, 8.5, and 24 hours post-dose. The results of this study showed that both montelukast and salmeterol protected against the effects of exercise at two and 8.5 hours postdose, but the protective effect of salmeterol had subsided by 24 hours (Figure 5). Montelukast patients still showed protection 24 hours post-treatment.

In another study, adults taking ICS with who continued to demonstrate EIB were either randomized to salmeterol bid or montelukast once daily for four weeks. At the end of the study montelukast patients not only showed less fall in $\mathrm{FEV}_{1}$ following exercise but had a greater response to a SABA (salbutamol, albuterol) when bronchoconstrictor rescue was needed. ${ }^{96}$ This would confirm previous studies that show the development of tolerance with regular $\beta_{2}$-agonist use. In a pediatric study of 32 children aged 6-12 years with EIB, tolerance to the protective effect of $5 \mathrm{mg}$ montelukast daily over a four-week treatment period was not found. ${ }^{97}$ The children exercised 20-24 hours after dosing after 3, 7, and 28 days of medication. Montelukast decreased the fall in $\mathrm{FEV}_{1}$ by about $50 \%$, whereas there was no change in $\mathrm{FEV}_{1}$ in children taking a placebo. It is important to remember that not all patients in a clinical trail respond equally.

Often what is reported or focused upon are the mean responses of the group. Clearly there are many patients who do better than the mean and many who do worse. Often the responder and nonresponder patients, when plotted on a graph, form a bell-shaped curve which might be quite symmetrical with approximately $50 \%$ responders and 50\% nonresponders. This is true with many diseases and has been demonstrated in both persistent asthma ${ }^{98,99}$ and EIB. ${ }^{85,86}$ There may also be the inability of an active medication to be effective in all clinical situations. For example, no effect was seen in a study of the effect of montelukast in the prevention of asthma-like symptoms in elite ice hockey players. ${ }^{100}$
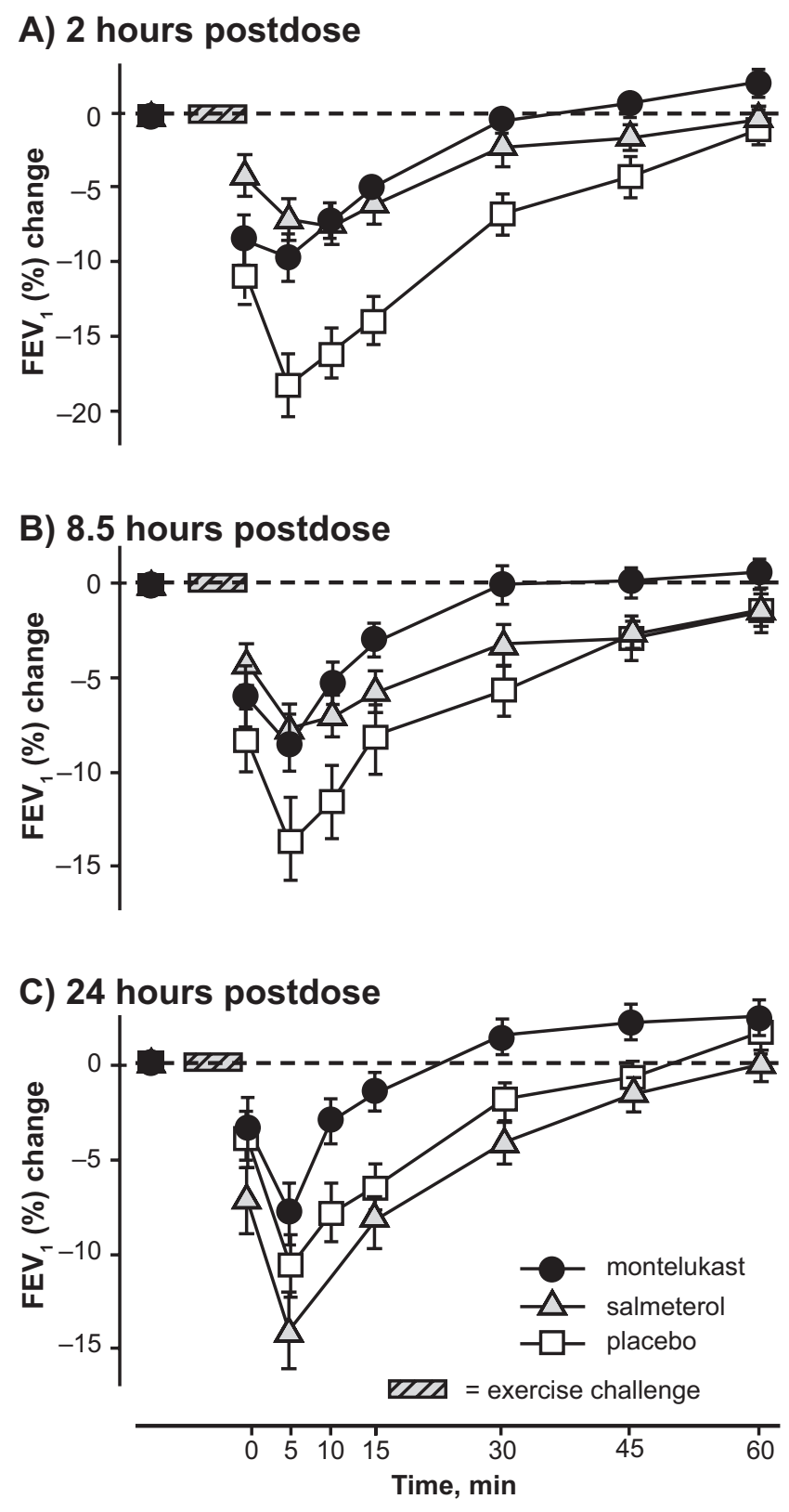

Figure 5 Mean $( \pm \mathrm{SE})$ percent changes in $\mathrm{FEV}$, after 2, 8.5, and 24 hours exercise challenge following treatment with montelukast, salmeterol, and placebo. Abbreviations: $\mathrm{FEV}_{\text {, }}$, forced expiratory volume in one second; SE, standard error.

One of the reasons patients or patient groups respond differently to a specific medication is very likely to be because of gene polymorphism. Two recent studies looked at gene polymorphisms in patients with EIB. ${ }^{101,102}$ In one of the studies it was demonstrated that Korean children with EIB had better response to a LTRA if they had a particular gene which resulted in a mechanism of inflammation (interleukin-13 [IL13]) that was more likely to involve leukotrienes. Therefore, no matter what treatment is chosen, it is important to have the patient with EIB return to the clinic for a reevaluation in 2-4 weeks as responses vary. 
During clinical trials of montelukast, very few adverse effects were reported by patients or found from review of laboratory test results. Most of the findings were similar to those found in placebo-treated patients and were commonly found in all patients: upper respiratory infection, sinusitis, headache, and cough. Shortly after marketing, reports of a severe vasculitis called Churg-Strauss syndrome (CSS) began to appear in some patients taking montelukast and other leukotriene-modifying medications. Although the FDA issued a warning about this syndrome appearing in patients taking leukotriene-modifying medications, the possibility that this condition might be the direct result of treatment with these agents remains unproven. No epidemic of CSS has developed since millions of doses of medications were prescribed over a decade of use. Although isolated cases of CSS have continued to be reported and some developed after patients were started on leukotriene-modifying therapy, the general consensus is that CSS was already present in the majority of cases before treatment with these new medications. It has been proposed that in many cases the reason CSS appeared was attributable to a decrease or elimination of systemic corticosteroids being used to treat this previously undiagnosed condition which often is associated with very severe asthma. ${ }^{103,104}$ However, this issue has not been resolved and in a review of 62 cases available on Medline as of 1997, the authors concluded that available evidence suggests an association between LTRA and CSS that may be causal. ${ }^{105}$

Recently reports of rare occurrences of neuropsychiatric events have been reported in patients taking montelukast, zafirlukast, and zileuton. These include behavior- and mood-related changes (agitation including aggressive behavior, bad/vivid dreams, depression, feeling anxious, hallucinations, irritability, restlessness, suicidal thoughts and actions [including suicide], tremor, or trouble sleeping). As a result, the $\mathrm{FDA}^{106}$ and pharmaceutical companies have included these findings in their prescribing information, although a cause-and-effect relationship has not yet been proven. Despite the general strong safety profile obtained from a decade of use and the rarity of reported adverse events with montelukast, prescribers should always be aware that rare and unexpected events can happen and may later be found to be associated with this medication and therapy of any kind.

\section{Conclusion}

Although EIB is a common finding in both adults and children with asthma, it can occur in patients who only wheeze following exercise. Although there is much yet to learn about the pathophysiology of this disorder, it is becoming clearer that the bronchoconstriction experienced by the patient is a result of hyperventilation of any type on an injured inflamed airway. Understanding of this underlying mechanism is important not only in directing the patient to proper medications, but in directing them to an exercise program that can allow adequate cardiovascular benefits.

It is important not to assume that all patients who present with respiratory symptoms during or following exercise have EIB. Clearly patients may be "out of shape" or overweight, but it is important to think about cardiovascular disorders or other conditions that are result in upper airway obstruction such as vocal cord dysfunction. It is very difficult to evaluate a patient with airway symptoms without an objective measurement of airway function. Studies have shown both an under- and over-diagnosis of the degree of airway obstruction or loss of lung function when only the history and physical examination are used. Spirometry has become so readily available and inexpensive, that today any patient with persistent or recurrent respiratory problems should be evaluated with pulmonary function tests.

When spirometry is not available, a therapeutic trial of a medication which should be effective in EIB may be enough to make the diagnosis. However since often there is a $30 \%$ or greater response rate to placebos in most disorders, objective documentation of the effect of the medication is important. Not only is documentation of responses to medication in a condition such as EIB is extremely important, regular follow up must be part of a management program for patients of any age or level and type of exercise.

For many compliant patients, keeping good control of their asthma will be enough to allow them to exercise adequately. Fortunately several medications have been proven to be effective in this disorder. These include ICS, SABA, LABA, cromones, and more recently medications that modify the effect of leukotrienes in the airway. In this category, the LTRA, montelukast, has been the drug most studied and currently is approved for the control of EIB in patients aged 15 years and older in many countries. Studies have shown an effect as soon as two hours after a single $10 \mathrm{mg}$ dose of montelukast. With multiple dosing, an effect can be demonstrated 24 hours after the last dose in many patients. Tolerance with repeated dosing has not been seen in clinical studies. Although reports of serious adverse effects have been reported in patients receiving montelukast and other leukotriene-modifying medications, the consensus is that there is little evidence of a causal relationship to 
these medications. Clinical research studies and regulatory approvals indicate that the LTRA, montelukast, is a reasonable medication to consider in patients with EIB.

\section{Disclosures}

The author reports being a member of the Merck (MSD) Speakers Bureau.

\section{References}

1. Aretaeus. On the causes and symptoms of chronic diseases. In: Adams F, editor/translator. The Extant Works of Aretaeus the Cappadocian. London, UK: Syndenham Society; 1856. book I, chap XI. p. 316-318.

2. Anderson SD, Fitch K, Perry CP, et al. Responses to bronchial challenge submitted for approval to use inhaled beta2-agonists before an event at the 2002 Winter Olympics. J Allergy Clin Immunol. 2003;111:44-49.

3. Fitch KD, Sue-Chu M, Anderson SD, et al. Asthma and the elite athlete: summary of the International Olympic Committee's consensus conference, Lausanne, Switzerland, January 22-24, 2008. JAllergy Clin Immunol. 2008:122(2):254-260.

4. Kindermann W. Do inhaled beta ${ }_{2}$ agonists have an ergogenic potential in non-asthmatic competitive athletes? Sports Med. 2007;37(2):95-102.

5. World Anti-Doping Agency. The World Anti-Doping Code. The 2008 prohibited list: International standard. Available at: http://www. wada-ama.org/rtecontent/document/2008_List_En.pdf. Accessed on February 10, 2009.

6. Anderson SD, Sue-Chu M, Perry CP, et al. Bronchial challenges in athletes applying to inhale a beta 2-agonist at the 2004 Summer Olympics. J Allergy Clin Immunol. 2006;117:767-773.

7. Koh MS, Tee A, Lasserson TJ, Irving LB. Inhaled corticosteroids compared to placebo for prevention of exercised induce bronchoconstriction. Cochrane Database Syst Rev. 2007;3:CD002739.

8. McFadden ER. Approach to the patient exercise induced narrowing. In: Adkinson Jr NF, Yunginger JW, Busse WW, Bochner BS, Simons FER, Holgate ST, editors. Middleton's Allergy Principals and Practice. 7th Ed. Philadelphia, PA: Mosby; 2009. Chap 78. p. 1385.

9. Mussaffi H, Springer C, Godfrey S. Increased bronchial responsiveness to exercise and histamine after antigen challenge in children with asthma. J Allergy Clin Immunol. 1986;77:48-52.

10. Cabral AL, Conceicao GM, Fonseca-Guedes CH, et al. Exerciseinduced bronchospasm in children: effects of asthma severity. Am J Respir Crit Care Med. 1999;159(6):1819-1823.

11. Turner SW, Young S, Goldblatt J, Landau LI, Le Souëf PN. Childhood asthma and increased airway responsiveness: a relationship that begins in infancy. Am J Respir Crit Care Med. 2009;179:98-104.

12. Deal EC Jr, McFadden ER Jr, Ingram RH Jr, Breslin FJ, Jaeger JJ. Airway responsiveness to cold air and hyperpnea in normal subjects and those with hay fever and asthma. Am Rev Respir Dis. 1980;121:621-628.

13. Turcotte H, Langdeau JB, Thibault G, Boulet LP. Prevalence of respiratory symptoms in an athlete population. Respir Med. 2003;97: 955-963.

14. Kujuala UM, Sarna S, Kaprio J, Koskenvuo M. Asthma and other pulmonary diseases in former elite athletes. Thorax. 1996;51:288-292.

15. Eggleston PA, Guerrant JL. A standard method of evaluating exercise induced asthma. J Allergy Clin Immunol. 1976;58(3):414-425.

16. Pearlman DS, van Adelsberg J, Philip G, et al. Onset and duration of protection against exercise-induced bronchoconstriction by a single oral dose of montelukast. Ann Allergy Immunol. 2006;97:98-104.

17. Shturman-Ellstein R, Zeballos RJ, Buckley JM, et al. The beneficial effect of nasal breathing on exercise-induced bronchoconstriction. Am Rev Respir Dis. 1978;118:65-73.

18. Anderson SD, Argyros GJ, Magnussen H, Holzer K. Provocation by eucapnic voluntary hyperpnoea to identify exercise induced bronchoconstriction. Br J Sports Med. 2001;35(5):344-347.
19. Anderson SD Brannan JD. Methods for "indirect" challenge tests including exercise, eucapnic voluntary hyperpnea and hypertonic aerosols. Clin Rev Allergy Immunol. 2003;24(1):27-54.

20. Anderson SD. Exercise-induced asthma and the use of hypertonic saline aerosol as a bronchial challenge. Respirology. 1996;1(3):175-181.

21. Carlsen KH, Engh G, Mork M. Exercised-induced bronchoconstriction depends on exercise load. Respir Med. 2000;94(8):750-755.

22. McFadden ER Jr, Zawadski DK. Vocal cord dysfunction masquerading as exercise induced asthma. a physiologic cause for "choking" during athletic activities. Am J Respir Crit Care Med. 1996;153(3): 942-947.

23. Ternesten-Hasséus E, Johansson EL, Bende M, Millqvist E. Dyspnea from exercise in cold air is not always asthma. $J$ Asthma. 2008;45(8): 705-709.

24. Teeter JG, Bleecher ER. Relationship between airway obstruction and respiratory symptoms in adult asthmatics. Chest. 1998;113(2): 272-277.

25. Crapo RO, Casaburi R, Coates AL, et al. Guidelines for methacholine and exercise challenge testing-1999. This official statement of the American Thoracic Society was adopted by the ATS Board of Directors, July 1999. Am J Respir Crit Care Med. 2000;161: 309-329.

26. Holzer K, Anderson SD, Chan HK, Douglass J. Mannitol as a challenge test to identify exercise-induced bronchoconstriction in elite athletes. Am J Respir Crit Care Med. 2003;167(4):534-537.

27. Brannan JD, Koskela H, Anderson SD, Chew N. Responsiveness to mannitol in asthmatic subjects with exercise and hyperventilationinduced asthma. Am J Respir Crit Care Med. 1998;158(4):1120-1126.

28. McFadden ER Jr, Lenner KA, Strohl KP. Postexertional airway rewarming and thermally induced asthma. New insights into pathophysiology and possible pathogenesis. J Clin Invest. 1986;78:18-25.

29. Anderson SD, Daviskas E. The mechanism of exercise-induced asthma is... J Allergy Clin Immunol. 2000;106(3):453-459.

30. Anderson SD, Kippelen P. Airway injury as a mechanism for exerciseinduced bronchoconstriction in elite athletes. J Allergy Clin Immunol. 2008;122(2):225-235.

31. Hallstrand TS, Moody MW, Aitken ML, Henderson WR Jr. Airway immunopathology of asthma with exercise-induced bronchoconstriction. J Allergy Clin Immunol. 2005;116(3):586-593.

32. Hallstrand TS, Moody MW, Wurfel MM, et al. Inflammatory basis of exercise- induced bronchoconstriction. Am J Respir Critical Care Med. 2005;172(6):679-686.

33. Helenius I, Haahtela T. Allergy and asthma in elite summer sport athletes. J Allergy Clin Immunol. 2000;106:444-452.

34. Uyan ZS, Carro S, Piacentini G, Bardaldi E. Swimming pool, respiratory health, and childhood asthma: should we change our beliefs? Pediatr Pulmonol. 2009;44(1):31-37.

35. Turcotte H, Langdeau JB, Thibault G, Boult LP. Prevalence of respiratory symptoms in an athletic population. Respir Med. 2003;97: 995-963.

36. Helenius I, Lumme A, Haahtela T. Asthma airway inflammation and treatment in elite athletes. Sports Med. 2005;35:565-574.

37. Langdeau JB, Turcotte H, Bowie DM, et al. Airway hyperresponsiveness in elite athletes. Am J Respir Crit Care Med. 2000;161(5): 1479-1484.

38. Carlsen KH, Anderson SD, Bjermer L, et al. Respiratory and allergic disorders in elite athletes: epidemiology, mechanisms and diagnosis: Part 1 of the report from the Joint Task Force of the European Respiratory Society (ERS) and the European Academy of Allergy and Clinical immunology (EAACI) in cooperation with GA2LEN. Allergy. 2008;63(4):387-403.

39. Langdeau JB, Day A, Turcotte H, Boulet LP. Gender differences in the prevalence of airway hyperresponsiveness and asthma in athletes. Respir Med. 2009;103(3):401-406.

40. Bonsignore MR, La Gutta S, Cibella F, et al. Effects of exercise training and montelukast in children with mild asthma. Med Sci Sports Exerc. 2008;40(3):405-412. 
41. Edmunds AT, Tooley M, Goodfrey S. The refractory period after exercise-induced asthma: its duration and relationship to the severity of exercise. Am Rev Respir Dis. 1978;117:247-254.

42. Bar-Yishay E, Ben-Dov I, Godfrey S. Refractory period after hyperventilation induced asthma. Am Rev Respir Dis. 1983;127:572-574.

43. Mickleborough TD, Lindley MR, Turner LA. Comparative effect of a high-intensity interval warm-up and salbutamol on the bronchoconstrictor response to exercise in asthmatic athletes. Int J Sports Med. 2007;28(6):456-462.

44. Cabral AL, Conceicao CM, Fonsecca-Guedes CM, Martins MA Exercise-induced bronchospasm in children: effects of asthma severity. Am J Respir Crit Care Med. 1999;159:1819-1823.

45. National Institutes of Health. Expert Panel Report 3: Guidelines for the Diagnosis and Management of Asthma. NIH Publication No.08-4051. Bethesda MD: US Department of Health and Human Services, National Institutes of Health, National Heart Lung and Blood Institute, National Asthma Education and Prevention Program;August 2007.

46. Bateman ED, Hurd SS, Barnes PJ, et al. Global strategy for asthma management and prevention: GINA executive summary. Eur Respir J. 2008;31:143-178.

47. Garcia-Aymerich J, Varraso R, Anto JM, Carmarargo Jr CA. Prospective study of physical activity and risk of asthma exacerbations in older women. Am J Respir Crit Care Med. 2009;179:999-1003.

48. Lima JJ, Blake KV, Tantisira KG, Weiss ST. Pharmacogenetics of asthma. Curr Opin Pulm Med. 2009;15(1):57-62.

49. Israel E. Genetics and variability of treatment responses in asthma. J Allergy Clin Immunol. 2005;115(4 Suppl):S532-S538.

50. Hartley JP, Davies BH. Cholinergic blockade in the prevention of exercise-induced asthma. Thorax. 1980;35(9):680-685.

51. Poppius H, Sovijärvi AR, Tammilehto L. Lack of protective effect of high-dose ipratropium on bronchoconstriction following exercise with cold air breathing in patients with mild asthma. Eur J Respir Dis. 1986;68(5):319-325.

52. Pasterkamp H, Tal A, Leahy F, Fenton R, Chernick V. The effect of anticholinergic treatment on postexertional wheezing in asthma studied by phonopneumography and spirometry. Am Rev Respir Dis. 1985;132(1):16-21.

53. Larsson K. Oxitropium bromide, ipratropium bromide and fenoterol in exercise-induced asthma. Respiration. 1982;43(1):57-63.

54. Koh MS, Tee A, Lasserson TJ, Irving LB. Inhaled corticosteroids compared to placebo for prevention of exercise induced bronchoconstriction. Cochrane Database Syst Rev. 2007;3:CD002739.

55. Kelloway JS, Wyatt RA, Adlis SA. Comparison of patient's compliance with prescribed oral and inhaled asthma medications. Arch Intern Med 1994;154:1349-1352.

56. Smith BW, LaBotz M. Pharmacologic treatment of exercise induced asthma. Clin Sports Med. 1998;17:343-336.

57. Anderson SD. Single-dose agents in the prevention of exercise-induced asthma: a descriptive review. Treat Respir Med. 2004;3:365-379.

58. Anderson SD, Brannan JD. Long-acting beta 2-adrenoceptor agonists and exercise-induced asthma: lessons to guide us in the future. Paediatr Drugs. 2004;6(3):161-175.

59. Anderson SD, Rodwell LT, Du Toit J, et al. Duration of protection by inhaled salmeterol in exercise-induced asthma. Chest. 1991;100: 1254-1260.

60. Nelson JA, Strauss L, Skowronski M, et al. Effect of long-term salmeterol treatment on exercise-induced asthma. $N$ Engl J Med. 1998;339:141-146.

61. Boner AL, Spezia E, Piovesan P, et al. Inhaled formoterol in the prevention of exercise induced bronchoconstriction in asthmatic children. Am J Respir Crit Care Med. 1994;149:935-939.

62. McAlpine LG, Thomson NC. Prophylaxis of exercise-induced asthma with inhaled formoterol, a long-acting beta 2-adrenergic agonist. Respir Med. 1990;84:293-295.

63. Simons EF, Gerstner TV, Cheang MS. Tolerance to the bronchoprotective effect of salmeterol in adolescents with exercise-induced asthma using concurrent inhaled glucocorticoid treatment. Pediatrics. 1997;99:655-659.
64. Ramage L, Lipworth BJ, Ingram CG, Cree IA, Dhillon DP. Reduced protection against exercise induced bronchospasm after chronic dosing with salmeterol. Respir Med. 1994;88:363-368.

65. Castle W, Fuller R, Hall J, et al. Serevent nationwide surveillance study: comparison of salmeterol with salbutamol in asthmatic patients who require regular bronchodilator treatment. $\mathrm{Br}$ Med J. 1993;306: 1034-1037.

66. Nelson HS, Weiss ST, Bleecker ER, Yancey SW, Dorinsky PM; SMART Study Group. The Salmeterol Multicenter Asthma Research Trial: a comparison of usual pharmacotherapy for asthma or usual pharmacotherapy plus salmeterol. Chest. 2006;129:15-26.

67. Summary minutes of the joint pulmonary-allergy drugs advisory committee (PADAC), drug safety and risk management advisory committee (DSaRM) and pediatric advisory committee (PAC). 2008. Dec 10-11, http://www.fda.gov/ohrms/ac/08/minutes/2008-4398m1-final.pdf.

68. Sears MR, Ottosson A, Radner F, Swissa S. Long-acting beta-agonists: a review of formoterol safety data from asthma clinical trials. Eur Respir J. 2009;33:21-32.

69. Morton AR, Ogle SL, Fitch KD. Effects of nedocromil sodium, cromolyn sodium, and a placebo in exercise-induced asthma. Ann Allergy. 1992;68(2):143-148.

70. Spooner C, Rowe BH, Sanders LD. Nedocromil sodium in the treatment of exercise-induced asthma: a meta-analysis. Eur Respir J. 2000; 16(1):30-37.

71. Spooner CH, Spooner GR, Rowe BH. Mast-cell stabilizing agents to prevent exercise induced bronchoconstriction. Cochrane Database Syst Rev. 2003;4:CD002307.

72. Israel E, Drazen JM. Role of 5-lipoxygenase metabolites of arachidonic acid in exercise-induced asthma. In: McFadden ER Jr, editor. Exerciseinduced Asthma. Vol. 130. New York. NY: Marcel Dekker, Inc; 1999. p.167-180.

73. O'Byrne PM. Leukotriene bronchoconstriction induced by allergen and exercise. Am J Respir Crit Care Med. 2000;161:S68-S72.

74. Bisgaard H. Role of leukotrienes in asthma pathology. Pediatr Pulmonol. 2000;30;166-176.

75. Philip G, Pearlman DS, Villaran C, et al. Protection against exerciseinduced bronchoconstriction by a single, oral dose of montelukast. J Asthma. 2007;44:213-217.

76. Pearlman DS, van Adelsberg J, Philip G, et al. Onset and duration of protection against exercise-induced bronchoconstriction by a single oral dose of montelukast. Ann Allergy Asthma Immunol. 2006;97: 98-104.

77. Kemp JP. Role of leukotriene receptor antagonists in pediatric asthma. Pediatr Pulmonol. 2000;30(2):177-182.

78. Manning PJ, Watson RM, Margolskee DJ, et al. Inhibition of exerciseinduced bronchoconstriction by MK-571, a potent leukotriene D4-receptor antagonist. $N$ Engl J Med. 1990;323:1736-1739.

79. Lehnigk B, Rabe KF, Dent G, et al. Effects of a 5-lipoxygenase inhibitor, ABT-761, on exercise-induced bronchoconstriction and urinary LTE4 in asthmatic patients. Eur Respir J. 1998;11: $617-623$.

80. Meltzer SS, Hasday JD, Cohn J, et al. Inhibition of exercise-induced bronchospasm by zileuton: a 5-lipoxygenase inhibitor. Am J Respir Crit Care Med. 1996;153:931-935.

81. Dessanges JF, Prefaut C, Taytard A, et al. The effect of zafirlukast on repetitive exercise induced bronchoconstriction: the possible role of leukotrienes in exercise-induced refractoriness. JAllergy Clin Immunol. 1999;104:1155-1161.

82. Pearlman DS, Ostrom NK, Bronsky EA, et al. The leukotriene D4-receptor antagonist zafirlukast attenuates exercise-induced bronchoconstriction in children. J Pediatr. 1999;134:273-279.

83. Suguro H, Majima T, Hattori T, et al. [Effect of a leukotriene antagonist, pranlukast hydrate, on exercise-induced asthma for 14 days]. Arerugi. 2000;49(8):646-652.

84. Zhao JJ, Rogers JD, Holland SD, et al. Pharmacokinetics and bioavailability of montelukast sodium (MK-0476) in healthy young and elderly volunteers. Biopharm Drug Dispos. 1997;18:769-777. 
85. Leff JA, Busse WW, Pearlman DS, Bronsky EA, Kemp JP. Montelukast, a leukotriene-receptor antagonist, for the treatment of mild asthma and exercise-induced bronchoconstriction. N Engl J Med. 1998;339: $147-152$.

86. Kemp JP, Dockhorn RJ. Shapiro GG, et al. Montelukast once daily inhibits exercise-induced bronchoconstriction in 6-14 year-old children with asthma. J Pediatrics. 1998:133(3):424-428.

87. Pradalier A. Late phase reaction in asthma: Basic mechanisms. Int Arch Allergy Immunol. 1993;101(3):322-325.

88. Verhoeff NP, Speelberg B, van den Berg NJ, Oosthoek CH, Stijnen T. Real and pseudo late asthmatic reactions after submaximal exercise challenge in patients with bronchial asthma. A new definition for late asthmatic responses after exercise challenge. Chest. 1990;98:1194-1199.

89. Karjalainen J. Exercise response in 404 young men with asthma: no evidence of a late asthmatic reaction. Thorax. 1991;46:100-104.

90. Lee TH, Nagukura T, Papageorgiou N, Tikura Y, Kay AB. Exercise induced late asthmatic reaction with chemotactic activity. $N$ Engl J Med. 1983;308(25):1502-1505.

91. Boulet LP, Legris C, Turcotte H, Hebert J. Prevalence and characteristics of late asthmatic responses to exercise. J Allergy Clin Immunol. 1987; 80(5):655-662.

92. Mello RE, Sole D, Naspitz CK. Exercise-induced bronchoconstriction in Children: Montelukast attenuates the immediate-phase and late-phase responses. J Allergy Clin Immunol. 2003;111(2); 301-307.

93. Booth H, Bish R, Walters J, Whitehead F, et al. Salmeterol tachyphylaxis in steroid treated subjects. Thorax. 1996;51(11):1100-1104.

94. Garcia R, Garcia P, Feo F, et al. Tachyphylaxis following regular use of formoterol in exercise-induced bronchospasm. J Investig Allergol Clin Immunol. 2001;11:176-182.

95. Edelman JM, Turpin JA, Bronsky EA, Grossman J, et al. Oral montelukast compared with inhaled salmeterol to prevent exercise induced bronchoconstriction. Ann Intern Med. 2000;132:97-104.

96. Storms W, Chervinsky P, Ghannam AF, Bird S, Hustad CM, Edelman JM; Challenge-Rescue Study Group. A comparison of the effects of oral montelukast and inhaled salmeterol on response to rescue bronchodilation after challenge. Respir Med. 2004;98(11):1051-1062.
97. de Benedictis FM, Del Giudice MM, Forenza N, et al. Lack of tolerance to the protective effect of montelukast in exercise-induced bronchoconstriction in children. Eur Respir J. 2006;28:291-295.

98. Malmstrom K, Rodriguez-Gomez G, Guerra J, et al. Oral montelukast, inhaled beclomethasone, and placebo for chronic asthma. A randomized, controlled trial. Montelukast/Beclomethasone Study Group. Ann Intern Med. 1999;130(6):487-495.

99. Szefler SJ, Baker JW, Uryniak T, et al. Comparative study of budesonide inhalation suspension and montelukast in young children with asthma. J Allergy Clin Immunol. 2007;120(5):1043-1050.

100. Helenius I, Lumme A, Ounap J, et al. No effect of montelukast on asthma-like symptoms in elite ice hockey players. Allergy. 2004; 59(1):39-44.

101. Kang MJ, Lee SY, Kim HB, et al. Association of IL-13 polymorphisms with leukotriene receptor antagonist drug responsiveness in Korean children with exercise-induced bronchoconstriction. Pharmacogenet Genomics. 2008;18(7):551-558.

102. Kim JH, Lee SY, Kim HB, et al. TBXA2R gene polymorphism and responsiveness to leukotriene receptor antagonist in children with asthma. Clin Exp Allergy. 2008;38(1):51-59.

103. Guilpain P, Pagnoux C, Lhote F, Mouthon L, Guillevin L. Antileukotrienes and Churg-Strauss syndrome. Presse Med. 2007; 36(5 Pt 2):890-894.

104. Wechsler ME, Finn D, Gunawardena D, et al. Churg-Strauss syndrome in patients receiving montelukast as treatment for asthma. Chest. 2000;117(3):708-713.

105. Nathani N, Little MA, Kunst H, Wilson D, Thickett DR. Churg-Strauss syndrome and leukotriene antagonist use: a respiratory perspective. Thorax. 2008;63(10):883-888.

106. US Food and Drug Administration. FDA requests labeling change for leukotriene modifiers. June 12, 2009. Available from: http://www. fda.gov/NewsEvents/Newsroom/PressAnnouncements/ucm 166293. htm. Accessed on July 10, 2009.
Therapeutics and Clinical Risk Management

\section{Publish your work in this journal}

Therapeutics and Clinical Risk Management is an international, peerreviewed journal of clinical therapeutics and risk management, focusing on concise rapid reporting of clinical studies in all therapeutic areas, outcomes, safety, and programs for the effective, safe, and sustained use of medicines. This journal is indexed on PubMed Central, CAS,

\section{Dovepress}

EMBase, Scopus and the Elsevier Bibliographic databases. The manuscript management system is completely online and includes a very quick and fair peer-review system, which is all easy to use. Visit http://www.dovepress.com/testimonials.php to read real quotes from published authors. 